\title{
The Role of Oxygen in the Regulation of Glucose Metabolism, Transport and the Tricarboxylic Acid Cycle in Pseudomonas aeruginosa
}

\author{
By COLIN G. MITCHELL† AND EDWIN A. DAWES* \\ Department of Biochemistry, University of Hull, Hull HU6 7RX, U.K.
}

(Received 21 May 1981)

\begin{abstract}
The effect of dissolved oxygen concentration on the metabolism of glucose in Pseudomonas aeruginosa was studied with chemostat cultures using both single-step and gradual transitions from either ammonium or glucose limitation to oxygen limitation and studying transient and steady states. The pathway of glucose metabolism was regulated by the availability of oxygen. The organism responded to oxygen limitation by adjusting its metabolism of glucose from the extracellular direct oxidative pathway, which produces gluconate and 2oxogluconate, to the intracellular phosphorylative route. This change was a consequence of decreased activities of glucose dehydrogenase and gluconate dehydrogenase and of the transport systems for gluconate and 2-oxogluconate, and an increased activity of glucose transport, while relatively high activities of hexokinase and glucose-6-phosphate dehydrogenase were maintained. Citrate synthase, isocitrate dehydrogenase and malate dehydrogenase activities responded to changes in dissolved oxygen concentration rather than to changes in the glucose or ammonium concentrations. The effect of oxygen limitation on the oxo-acid dehydrogenases and aconitase was probably due, wholly or in part, to repression by glucose consequent upon the increase in residual glucose concentration. Succinate dehydrogenase was repressed by an increase in ammonium concentration under an oxygen limitation.
\end{abstract}

\section{INTRODUCTION}

Studies on the effects of dissolved oxygen concentration on the enzymic activities and metabolic versatility of obligate aerobes are relatively meagre compared with those on facultative anaerobes. This is understandable in view of the diversity of fermentation patterns encountered with the latter organisms on their transition from aerobic to anaerobic conditions (for recent reviews, see Harrison, 1976; Stouthamer, 1978; Jones, 1979). However, in their natural habitat obligate aerobes encounter a wide range of oxygen concentrations. Nitrogen-fixing azotobacters exhibit the phenomenon of respiratory protection; in these organisms high oxygen concentrations are toxic, inhibiting nitrogenase (Parker, 1954; Phillips \& Johnson, 1961; Dalton \& Postgate, 1969). Studies on the effect of oxygen on the enzymic complement of Azotobacter chroococcum and Azotobacter vinelandii have been carried out (Drozd \& Postgate, 1970; Haaker \& Veeger, 1976). We have previously shown that the energy-reserve polymer poly- $\beta$-hydroxybutyrate (PHB) accumulates in Azotobacter beijerinckii when cultures become oxygen-limited; the reductive stage of polymer synthesis serves as an alternative electron acceptor when oxygen is no longer so readily available, and thus permits the organism to grow under such conditions (Senior et al., 1972; Senior \& Dawes, 1973; Ward et al., 1977). The activities of key enzymes of PHB metabolism and of certain enzymes of the tricarboxylic acid cycle responded to changes in oxygen concentration

† Present address: Department of Biochemistry, University of Bath, Claverton Down, Bath BA2 7AY, U.K. 
(Jackson \& Dawes, 1976) but the Entner-Doudoroff enzymes were not affected (Stephenson et al., 1978; Carter \& Dawes, 1979).

The observed regulation of tricarboxylic acid cycle activity by oxygen concentration in $A$. beijerinckii posed the question of whether this behaviour was representative of obligate aerobes in general or whether it was a manifestation of respiratory protection and therefore characteristic only of nitrogen-fixing organisms. As we have previously studied the aerobe Pseudomonas aeruginosa, which is a denitrifier that utilizes glucose via the EntnerDoudoroff and tricarboxylic acid cycle pathways, we chose this organism for a comparative study of oxygen effects. Pseudomonas aeruginosa also metabolizes glucose via an extracellular direct oxidative pathway to gluconate and 2-oxogluconate $(\mathrm{Ng} \&$ Dawes, 1973; Midgley \& Dawes, 1973; Roberts et al., 1973; Whiting et al., 1976a, b). Transport of glucose, gluconate and 2-oxogluconate occurs by independently regulated systems (Whiting et al., 1976a) and the extracellular oxidative enzymes and associated transport systems are repressed when the organism is transferred from ammonium to glucose limitation (Whiting et $a l ., 1976 b$ ). Hunt \& Phibbs (1977) observed that the extracellular route was also repressed when $P$. aeruginosa was grown anaerobically with nitrate as electron acceptor in batch culture. It was of interest to examine the effect of varying oxygen concentration on the pathways of glucose metabolism in $P$. aeruginosa under the controlled conditions of the chemostat. We have thus examined the effect of transitions from ammonium or glucose limitation to oxygen limitation on various enzymes of glucose metabolism and the tricarboxylic acid cycle, and also on the transport systems for glucose, gluconate and 2-oxogluconate.

\section{METHODS}

Organism and growth. Pseudomonas aeruginosa PAO1 was kindly provided by Professor B. W. Holloway. Routine maintenance, batch growth of the organism and harvesting procedures were as previously described $(\mathrm{Ng}$ \& Dawes, 1973; Midgley \& Dawes, 1973). For chemostat inocula, the organism was subcultured at least ten times in the appropriate medium. All cultures were grown at $37^{\circ} \mathrm{C}$.

The chemostat vessel $(2.51$ volume $)$ was built in this Department. It was fitted with automatic $\mathrm{pH}$ control (E.I.L. Instruments, Richmond, Surrey; with pH electrodes supplied by Activion, Kinglassie, Fife), temperature control (Fielden Electronics, Manchester) and oxygen control (Leeds \& Northrup, Birmingham; Precision Products and Controls, Tulsa, U.S.A.). The oxygen electrodes were made in this Department. $\mathrm{CO}_{2}$ was measured with an infrared analyser (Mine Safety Appliances, Glasgow) and oxygen with a paramagnetic oxygen analyser (Servomex OA 137; Servomex Controls, Crowborough, Sussex). Continuous readout of gas composition was obtained with a Kent chart recorder (George Kent, Luton, Beds). The total gas flow was $11 \mathrm{~min}^{-1}$ and the required dissolved oxygen tension (d.o.t.) was secured by adjusting the proportion of oxygen in the inflowing oxygen/ nitrogen gas mixture. Oxygen limitation (undetectable d.o.t.) occurred at $4.5 \%(\mathrm{v} / \mathrm{v}$ ) oxygen in the inflowing gas.

Medium for continuous cultivation was prepared in 401 batches which were sterilized by filtration through a Sartorius filter $(142 \mathrm{~mm}$ diam., pore size $0.25 \mu \mathrm{m})$ at $292 \mathrm{kPa}$. The medium contained (per litre): $\mathrm{KH}_{2} \mathrm{PO}_{4}, 5.4 \mathrm{~g}$; nitrilotriacetic acid, $0.286 \mathrm{~g} ;\left(\mathrm{NH}_{4}\right)_{2} \mathrm{SO}_{4}, 0.9 \mathrm{~g}$ (for ammonium-limited growth) or $1.8 \mathrm{~g}$ (for glucose- and oxygen-limited growth); trace metal solutions $1(5 \mathrm{ml}), 2(5.25 \mathrm{ml})$ and $3(0.1 \mathrm{ml})(\mathrm{Ng} \&$ Dawes, 1973); glucose, $4.0 \mathrm{~g}$ (for carbon-limited growth) or $8.11 \mathrm{~g}$ (for ammonium-limited growth). For most of the single-step transitions from ammonium- or glucose-limited growth to oxygen limitation, the inflowing medium was simultaneously changed to furnish excess ammonium or glucose. Initial studies were carried out to ascertain the effect of such additions of ammonium or glucose, as noted in the Results. In the gradual transition experiments with ammonium-limited cultures, the inflowing medium was changed to provide excess ammonium as soon as ammonium ions could be detected in the medium supernatant; this occurred at approximately $9 \%$ oxygen in the inflowing gas. In similar experiments with glucose-limited cultures, glucose was detected in the supernatant at between 6 and $8 \%$ oxygen in the inflowing gas and the medium was changed at $4 \%$ oxygen to ensure an excess of glucose.

Six to ten vessel volumes were allowed to pass through the fermenter between each steady state before sampling except in experiments to study transient responses.

Transport studies. These were performed by the methods of Midgley \& Dawes (1973) using the substrate concentrations and specific radioactivities specified by Whiting et al. (1976b). The radioactivity was assayed as described by Midgley \& Dawes (1973). 
Enzyme assays. Bacterial extracts were prepared by the methods of $\mathrm{Ng} \&$ Dawes (1973). All enzyme assays were performed in cuvettes of $1 \mathrm{~cm}$ light-path at $37^{\circ} \mathrm{C}$ with a Pye Unicam SP 1800 recording spectrophotometer under previously determined optimum conditions. Specific activities are recorded as $\mu \mathrm{mol} \mathrm{h}^{-1}(\mathrm{mg} \text { protein })^{-1}$ and are the means of at least two assays which did not differ by more than $5 \%$.

The enzymes of glucose and 2-oxogluconate metabolism Iglucose dehydrogenase (EC 1.1.1.47), gluconate dehydrogenase (EC 1.1.99.3), glucose-6-phosphate dehydrogenase (EC 1.1.1.49), hexokinase (EC 2.7.1.1) and gluconate kinase (EC 2.7.1.12)] were assayed under the conditions described by $\mathrm{Ng}$ \& Dawes (1973) except that glucose dehydrogenase was assayed in the presence of phenazine methosulphate $(2 \mathrm{~mm})$. The combined activity of 2-oxogluconate kinase and 2-oxo-6-phosphogluconate reductase (referred to as 2-oxogluconate enzymes) was assayed by the method of Whiting et al. (1976 b). Isocitrate dehydrogenase (EC 1.1.1.42) and aconitase (EC 4.2.1.3) were assayed as described by $\mathrm{Ng} \&$ Dawes (1973); fumarate hydratase (EC 4.2.1.2) by the method of Racker (1950); citrate synthase (EC 4.1.3.7) according to Weitzman \& Dunmore (1969); malate dehydrogenase (EC 1.1.1.37) by the method of von Tigerström \& Campbell (1966) except that $5 \mathrm{mM}-\mathrm{MgCl}_{2}$ was included and the $\mathrm{pH}$ was 8.6; pyruvate dehydrogenase (EC 1.2.4.1) and 2-oxoglutarate dehydrogenase (EC 1.2.4.2) by the method of von Tigerström \& Campbell (1966) except that $\mathrm{Mg}^{2+}$ was omitted in the latter assay; succinate dehydrogenase (EC 1.3.99.1) by the method of Veeger et al. (1969); and NADH oxidase according to Jackson \& Dawes (1976). Both pyruvate and 2-oxoglutarate dehydrogenases were assayed under anaerobic conditions in cuvettes fitted with side-arms, on account of the high NADH oxidase activities of bacterial extracts. Cuvettes were flushed with oxygen-free nitrogen for $5 \mathrm{~min}$ and an airtight seal was achieved with Subaseal caps. Nitrogen was flushed for a further $5 \mathrm{~min}$ via syringe needles penetrating the Subaseals. Cuvettes were incubated for $10 \mathrm{~min}$ in the spectrophotometer at $37^{\circ} \mathrm{C}$ and the reaction was started by tipping the substrate from the side-arm. In control experiments for endogenous NAD reduction, water replaced the substrate. Combined EntnerDoudoroff enzymes [6-phosphogluconate dehydratase (EC 4.2.1.12) and 2-keto-3-deoxy-6-phosphogluconate aldolase (EC 4.1.2.14)] were jointly assayed by measuring the 6-phosphogluconate-dependent production of pyruvate coupled to the oxidation of NADH at $340 \mathrm{~nm}$ using an excess of commercial lactate dehydrogenase. Cuvettes contained (total volume $3 \mathrm{ml}$ ): $0.1 \mathrm{M}$-triethanolamine $/ \mathrm{HCl}$ buffer, $\mathrm{pH} 7.8,2 \mathrm{ml} ; 80 \mathrm{~mm}$-dithiothreitol, $0.2 \mathrm{ml} ; 10 \mathrm{~mm}-\mathrm{NADH}, 0.2 \mathrm{ml} ; 0.2 \mathrm{M}-6$-phosphogluconate, $0.1 \mathrm{ml}$; lactate dehydrogenase $\left(2 \mathrm{mg} \mathrm{ml}^{-1}\right), 0.2 \mathrm{ml}$; cell extract, $100 \mu$ l.

Analyses. Protein was estimated by the methods of Gornall et al. (1949) and Lowry. Glucose was determined with a glucose oxidase kit (Boehringer) and 2-oxogluconate by the method of Lanning \& Cohen (1951). Gluconate was determined by coupling gluconate kinase with gluconate-6-phosphate dehydrogenase according to the Boehringer Handbook. Ammonia was determined by the method of Chaney \& Marbach (1962).

Chemicals. $\left[\mathrm{U}-{ }^{14} \mathrm{C}\right.$ Glucose and $\left[\mathrm{U}-{ }^{14} \mathrm{C}\right]$ gluconate were obtained from Amersham. $2-\mathrm{Oxo}\left[{ }^{14} \mathrm{C}\right]$ gluconate was prepared by the method of Whiting et al. $(1976 \mathrm{~b})$. The following chemicals were obtained from Sigma: DL-isocitrate, phenazine methosulphate, DL-dithiothreitol, L-malate, 2-oxoglutarate (monosodium and monopotassium), 5,5'-dithiobis-(2-nitrobenzoic acid), 6-phosphogluconate, NAD (reduced and oxidized forms), NADPH, coenzyme A, $S$-acetyl-coenzyme A and glucose 6-phosphate. NADP was obtained from Boehringer. $\mathrm{L}$-Cysteine. $\mathrm{HCl}$ and oxaloacetic acid were from BDH. All other chemicals were of AnalaR standard or the highest purity available.

Enzymes. All commercial enzymes were obtained from Sigma.

\section{RESULTS AND DISCUSSION}

Two types of transition to oxygen limitation were used. The first, referred to as a single-step transition, subjected ammonium- or glucose-limited cultures to a sudden decrease from a high to an undetectable dissolved oxygen tension (d.o.t.). In the second, the d.o.t. was lowered in stages, and is termed a gradual transition.

\section{Effects of oxygen concentration: single-step transitions}

The transition from ammonium limitation to oxygen limitation resulted in decreases in the specific activities of glucose, gluconate and glucose-6-phosphate dehydrogenases, gluconate kinase and the 2-oxogluconate enzymes, while hexokinase increased in activity (Table 1). With the exception of gluconate kinase and the 2-oxogluconate enzymes, new steady-state activities were reached within $40 \mathrm{~h}$ of the transition, as were the residual nutrient concentrations. The activity of glucose dehydrogenase decreased 20 to $30 \%$ faster than that of gluconate dehydrogenase. 


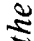

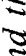

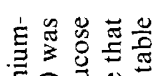

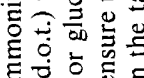

$<0$

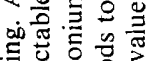

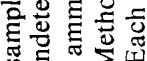

远政

过可.

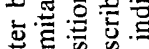

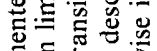

\%

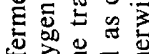

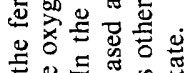

E

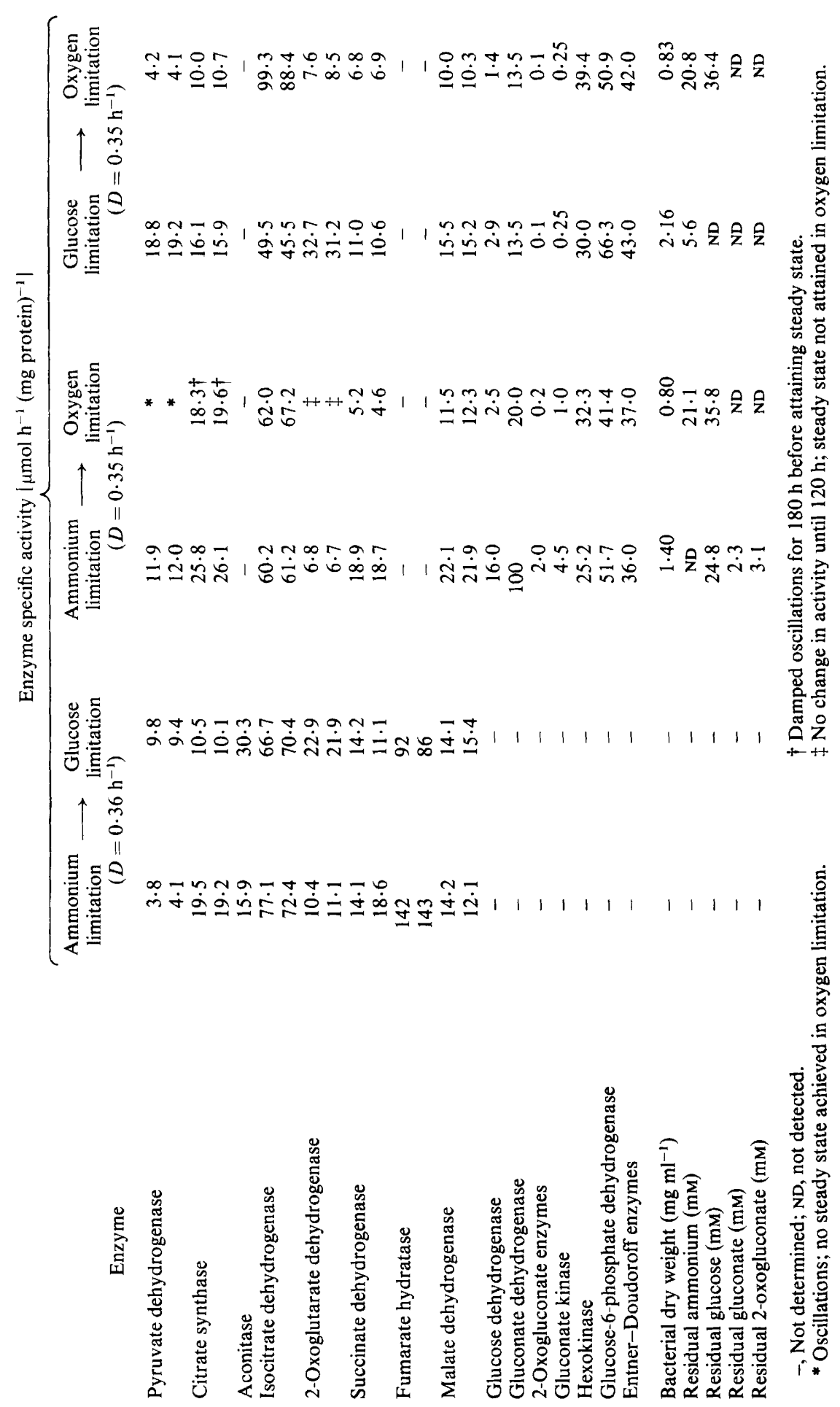

政自

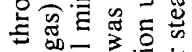

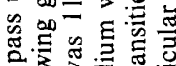

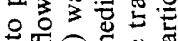

可言

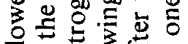

ส. $\Xi$ 光

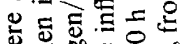

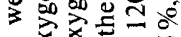

is $8 x=0$ in

ธิ ธิ

จ

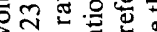

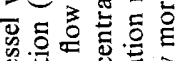

ธี.

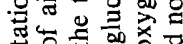

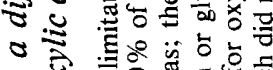

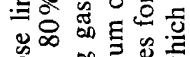
政

E气

\& $3 . \Xi$ ह

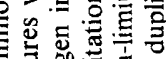

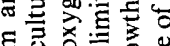

ह

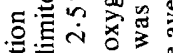

¿ $\quad: 5$

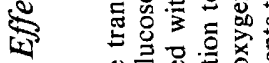

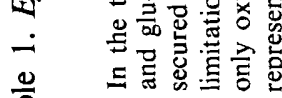

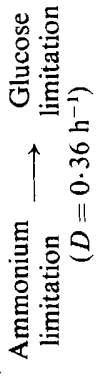

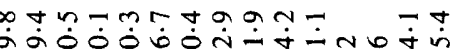

茎 


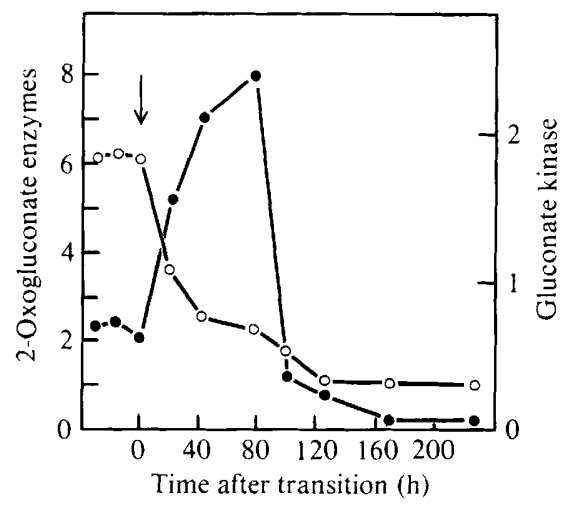

Fig. 1. Effect of single-step transition to oxygen limitation (undetectable d.o.t.) of an ammonium-limited culture on the activities of gluconate kinase $(O)$ and the 2 -oxogluconate enzymes (O). At the time indicated by the arrow, the oxygen supply rate in the oxygen/nitrogen mixture was decreased from 230 to $25 \mathrm{ml} \mathrm{min}{ }^{-1}$ (total gas flow $1 \mathrm{I} \mathrm{min}^{-1}$ ) and the $\left(\mathrm{NH}_{4}\right)_{2} \mathrm{SO}_{4}$ concentration in the inflowing medium was increased from 0.9 to $1.8 \mathrm{~g} \mathrm{l}^{-1}: D=0.35 \mathrm{~h}^{-1}$. Enzyme specific activities are expressed as $\mu \mathrm{mol} \mathrm{h}^{-1}(\mathrm{mg}$ protein) ${ }^{-1}$.

Table 2. Effect of a single-step transition to oxygen limitation of an ammonium-limited culture on the steady-state activities of the transport systems for glucose, gluconate and 2-oxogluconate

The conditions were as described in Fig. 1. The activities for oxygen limitation are steady-state values obtained $110 \mathrm{~h}$ after the transition; activities oscillated during the initial $100 \mathrm{~h}$ period.

$\begin{array}{lcc}\text { Transport system } & \overbrace{\begin{array}{c}\text { Ammonium } \\ \text { limitation }\end{array}}^{\text {Activity }\left[\mu \mathrm{mol} \mathrm{min}^{-1}\left(\mathrm{~g} \mathrm{dry} \mathrm{wt}^{-1}\right]\right.} \\ \text { Glucose } & 1.5 & \begin{array}{c}\text { Oxygen } \\ \text { limitation }\end{array} \\ \text { Gluconate } & 5 \cdot 5 & 5 \cdot 5 \\ \text { 2-Oxogluconate } & 105 & 3 \cdot 0 \\ & & 43\end{array}$

A similar response for hexokinase and glucose-6-phosphate dehydrogenase was observed in the transition from glucose limitation to oxygen limitation (Table 1). The EntnerDoudoroff enzymes were unchanged in transitions from ammonium or glucose limitation to oxygen limitation. In the latter transition, gluconate dehydrogenase was unchanged while glucose dehydrogenase decreased slightly in activity (Table 1). Gluconate, which is known to induce gluconate dehydrogenase (Whiting et al., 1976a), was not detected in the medium during the transition which probably accounts for the invariance of this enzyme. This interpretation is supported by the anaerobic batch culture studies of Hunt \& Phibbs (1977).

In transitions from ammonium to oxygen limitation the 2-oxogluconate enzymes increased markedly in activity up to $80 \mathrm{~h}$, before falling to a new steady-state level (Fig. 1). A similar response was observed for an initially glucose-limited culture. The reasons for this peak are not apparent but it may reflect transient changes in intracellular metabolite concentrations as a consequence of abrupt oxygen limitation. This response was observed on each occasion the experiment was performed, although the peak height did vary.

Transition from ammonium to oxygen limitation also resulted in an increase in the initial rate of glucose transport and decreases in those of gluconate and 2-oxogluconate (Table 2). In contrast, transition from glucose to oxygen limitation gave no change in these initial rates. This correlates with the virtual absence from the culture of gluconate and 2-oxogluconate (Table 1), compounds which induce their respective transport systems, while gluconate 


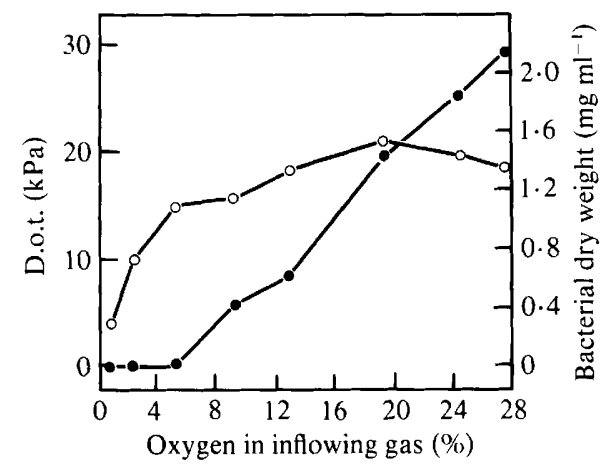

Fig. 2. Relationship between the percentage of oxygen in the inflowing gas, dissolved oxygen tension (O) and bacterial dry weight $(\mathrm{O})$ of an ammonium-limited culture. The required d.o.t. was achieved by varying the proportions of oxygen and nitrogen in a total gas flow rate of $11 \mathrm{~min}^{-1}: D=0.36 \mathrm{~h}^{-1}$.

additionally represses the activity of the glucose transport system (Whiting et al., 1976a). The decrease in the residual concentrations of these compounds probably explains the changes observed in transport rate in the transition from ammonium to oxygen limitation. The transport systems showed oscillations in the transition from ammonium to oxygen limitation, a new steady state being reached after $100 \mathrm{~h}$ (Table 2). The reasons for this response are unclear. No oscillations in the concentrations of glucose, gluconate or 2-oxogluconate were observed. Oscillations in the concentration of some intracellular modulator or metabolite may have given rise to this response, as may also be the case for the 2-oxogluconate enzymes. However, further study is required to clarify this behaviour.

The effect of both transitions on various tricarboxylic acid cycle enzymes is recorded in Table 1. Most showed a decrease in activity under oxygen limitation, while isocitrate dehydrogenase activity was unchanged in the transition from ammonium limitation but increased in activity in the transition from glucose limitation. Steady-state enzyme activities in organisms that had been changed from ammonium to oxygen limitation were much less stable than in those that had initially been glucose-limited. Pyruvate dehydrogenase did not reach a steady state within $240 \mathrm{~h}$, while citrate synthase showed damped oscillations, reaching a steady state after $180 \mathrm{~h}$. The residual nutrient concentration and bacterial dry weight reached new steady-state values after $40 \mathrm{~h}$. These oscillations may be due to changes in intracellular modulator concentrations, as a consequence of the severe oxygen limitation. Why they were not observed in the transition from glucose to oxygen limitation is not apparent and further study is needed.

To differentiate between glucose rather than oxygen acting as a repressive agent in these experiments, the effect of glucose limitation on an ammonium-limited culture was examined (Table 1). Isocitrate, succinate and malate dehydrogenases were unaffected by glucose limitation, while the two oxo-acid dehydrogenases and aconitase increased in activity. The effect of oxygen on the last three enzymes may thus be due, wholly or in part, to glucose repression. Citrate synthase and fumarate hydratase decreased in activity in glucose limitation. The response observed in oxygen limitation suggests that these enzymes may respond to low d.o.t. Experiments with ammonium-limited, oxygen-excess cultures, in which the residual steady-state glucose concentration was raised from 25 to $36 \mathrm{~mm}$, showed that the enzyme and transport activities remained constant. Thus, the changes observed when an ammonium-limited culture was oxygen-limited are not due to the increase in the residual glucose concentration.

A transient peak was observed for NADH oxidase when glucose- or ammonium-limited cultures were oxygen-limited, the maximum activity occurring after $40 \mathrm{~h}$; a new steady state was reached after $120 \mathrm{~h}$. The new steady-state activity was usually slightly higher. This 


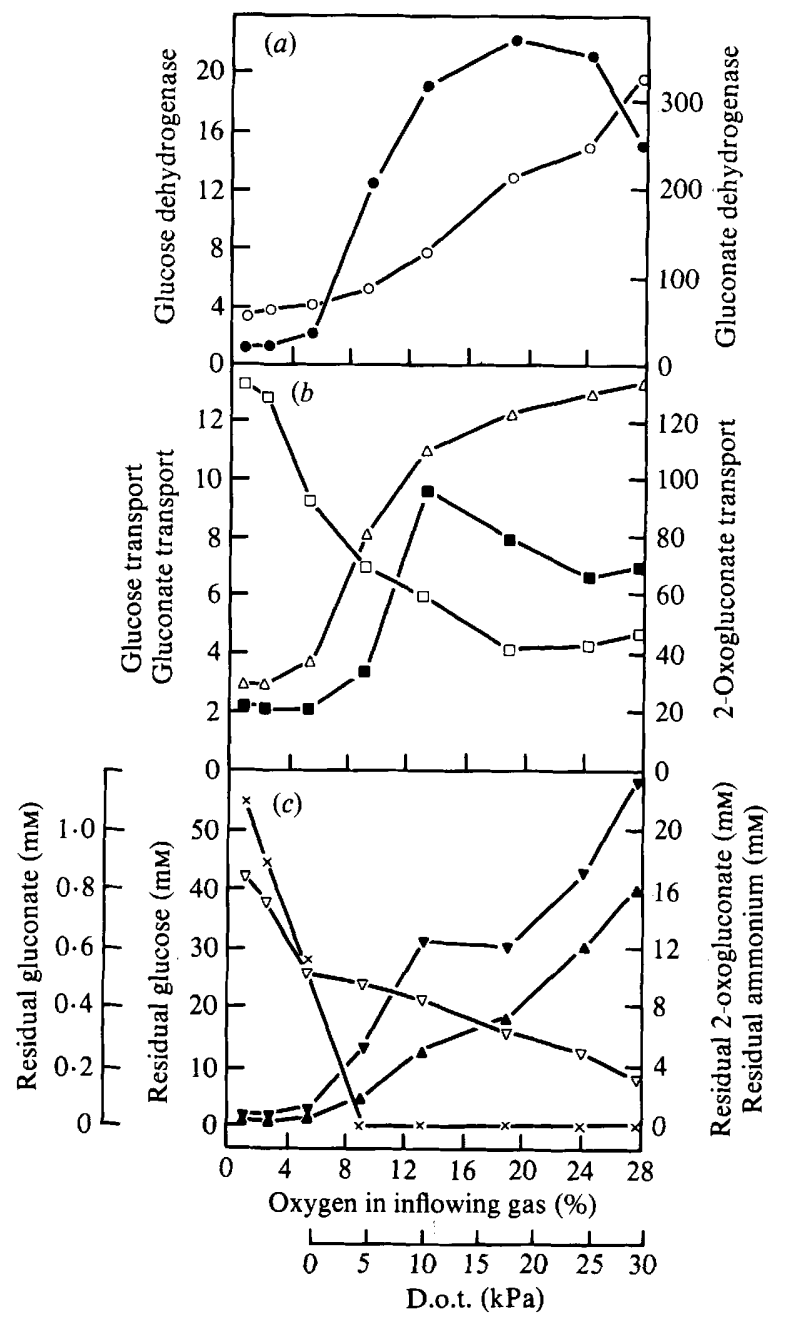

Fig. 3. Effect of gradual transition to oxygen limitation of an ammonium-limited culture on $(a)$ steady-state activities of glucose dehydrogenase $(O)$ and glucovate dehydrogenase $(O),(b)$ steady-state activities of the transport systems for glucose $(\square)$, gluconate $(\square)$ and 2-oxogluconate $(\triangle)$, and $(c)$ residual medium concentrations of glucose $(\nabla)$, gluconate $(\nabla)$, 2-oxogluconate $(\boldsymbol{\Delta})$ and ammonium $(\times)$. The conditions were those described for Fig. 2: all values refer to steady states. Enzyme specific activities are expressed as $\mu \mathrm{mol} \mathrm{h} \mathrm{h}^{-1}$ (mg protein) ${ }^{-1}$. Transport activities are expressed as $\mu \mathrm{mol} \mathrm{min}^{-1}$ (g dry wt) $)^{-1}$.

behaviour is quite different from the response of $A$. beijerinckii in which the enzyme is induced at high d.o.t. (Jackson \& Dawes, 1976). Further investigation is required to elucidate the reasons for this transient peak.

\section{Effects of oxygen concentration: gradual transitions}

In the transition from ammonium limitation to oxygen limitation, the d.o.t. showed a linear relationship to the partial pressure of oxygen in the inflowing gas (Fig. 2). The cell yield displayed a peak at $20 \%(\mathrm{v} / \mathrm{v})$ oxygen, possibly because oxygen was toxic at higher d.o.t. values. Glucose dehydrogenase activity decreased with d.o.t., accompanied by an increase in the residual concentration of glucose and a decrease in those of gluconate and 2-oxogluconate (Fig. $3 a, c)$. Glueonate dehydrogenase did not decrease significantly until the glucose 


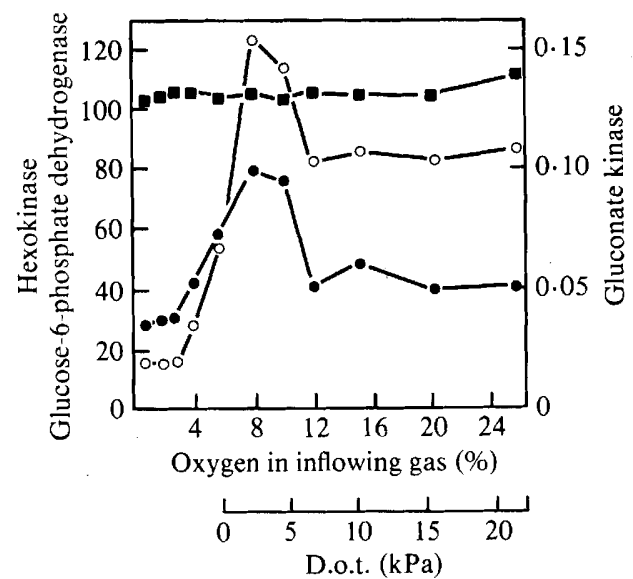

Fig. 4. Effect of gradual transition to oxygen limitation of a glucose-limited culture on the steady-state activities of hexokinase ( $(0)$, gluconate kinase $(\square)$ and glucose-6-phosphate dehydrogenase $(O)$. When the oxygen supply in the inflowing gas had been decreased to $4 \%$, the glucose concentration in the inflowing medium was increased from 4.0 to $8.11 \mathrm{~g}^{-1}$ to ensure that glucose was in excess: $D=$ $0.36 \mathrm{~h}^{-1}$. Enzyme specific activities are expressed as $\mu \mathrm{mol} \mathrm{h}^{-1}$ (mg protein $)^{-1}$.

dehydrogenase activity had fallen by two-thirds and the gluconate concentration by one-half. As in the single-step experiments, glucose dehydrogenase decreased in activity faster than gluconate dehydrogenase, supporting its role as a central control point in glucose metabolism. In the transition from glucose limitation, gluconate dehydrogenase was unchanged in activity, while glucose dehydrogenase showed a further decrease when the culture approached oxygen limitation, confirming the single-step transition result.

In the transition from ammonium limitation, glucose transport activity remained constant until the d.o.t. reached $18 \mathrm{kPa}$, when it started to increase (Fig. $3 \mathrm{~b}$ ). This rise was associated with a decrease in residual gluconate concentration. Gluconate transport activity initially increased slightly as the d.o.t. was decreased, but both gluconate and 2-oxogluconate transport activities declined markedly below $10.65 \mathrm{kPa}$ d.o.t. No change in activity for these systems was observed in the transition from glucose limitation, confirming the single-step studies.

The transition from glucose to oxygen limitation resulted in an initial increase in activity of glucose-6-phosphate dehydrogenase and hexokinase between 7.0 and $3.5 \mathrm{kPa}$ d.o.t., prior to the decline observed in oxygen limitation (Fig. 4). Gluconate kinase did not respond to the change in d.o.t. while the 2-oxogluconate enzymes were completely repressed in glucose limitation. Although the Entner-Doudoroff enzymes displayed approximately the same specific activity [45 to $50 \mu \mathrm{mol} \mathrm{h}{ }^{-1}$ (mg protein) ${ }^{-1}$ l under both glucose and oxygen limitation, a sharp rise in activity occurred below $7 \mathrm{kPa}$ d.o.t., reaching a peak of $120 \mu \mathrm{mol}$ $\mathrm{h}^{-1}$ (mg protein $)^{-1}$ at $5.3 \mathrm{kPa}$ and then declining as the culture became oxygen-limited.

In a similar transition from glucose limitation, all the tricarboxylic acid cycle enzymes decreased in activity as the d.o.t. was lowered, except isocitrate dehydrogenase which increased slightly in activity (Fig. 5). Pyruvate dehydrogenase and aconitase activities did not decrease until glucose appeared in the culture. To establish the effect of d.o.t. on these catabolite-sensitive enzymes, further investigations with a different carbon source are necessary. NADH oxidase remained relatively constant in activity, except for a peak at $7 \cdot 0 \mathrm{kPa}$ d.o.t.

In both types of transition experiment, the effect of oxygen was shown to be reversible, eliminating the possibility of variant selection being responsible. 


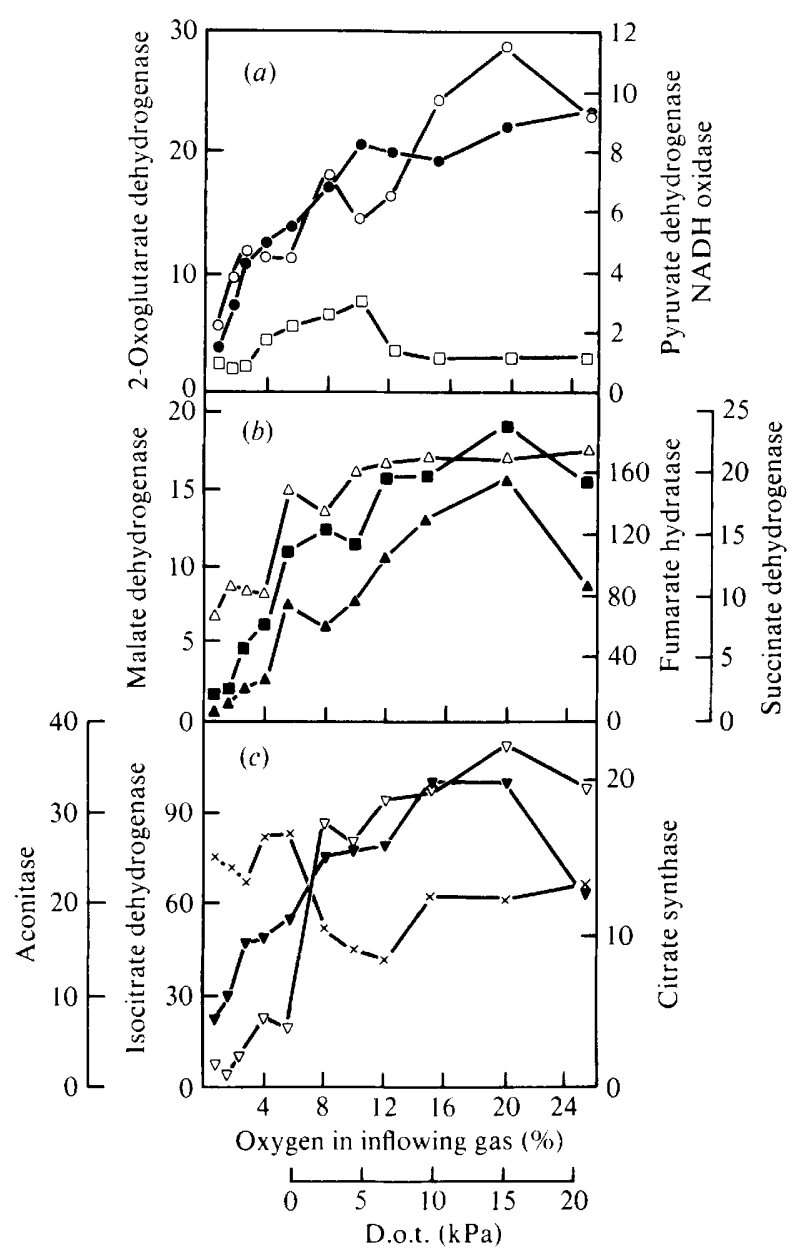

Fig. 5. Effect of gradual transition to oxygen limitation of a glucose-limited culture on steady-state activities of tricarboxylic acid cycle enzymes and NADH oxidase: $(a)$ pyruvate dehydrogenase $(\bigcirc)$, 2-oxoglutarate dehydrogenase $(O)$ and $\mathrm{NADH}$ oxidase $(\square) ;(b)$ succinate dehydrogenase $(\triangle)$, fumarate hydratase $(\boldsymbol{\Delta})$ and malate dehydrogenase $(\boldsymbol{\square}) ;(c)$ citrate synthase $(\boldsymbol{\nabla})$, aconitase $(\nabla)$ and isocitrate dehydrogenase $(x)$. The conditions were those described for Fig. 4. Enzyme specific activities are expressed as $\mu \mathrm{mol} \mathrm{h}{ }^{-1}$ (mg protein) $)^{-1}$.

Our experiments clearly demonstrate that oxygen limitation of $P$. aeruginosa causes a diversion of glucose metabolism from the extracellular oxidative pathway to the intracellular phosphorylative route. This pattern of behaviour was previously observed when a glucose limitation was imposed on an ammonium-limited culture (Whiting et al., 1976 b) and when the organism was grown anaerobically with nitrate in batch culture (Hunt \& Phibbs, 1977). The enzymes and transport systems of the extracellular route are all decreased under oxygen limitation and it is apparent from the gradual transition experiments that they start to be affected when the d.o.t. falls below air saturation. The possibility that the observed effects might be attributed, at least in part, to nitrogen catabolite repression or to changes in the availability of ammonia was investigated by comparing the results recorded in Table 1 with those of experiments in which no ammonium addition was made when the oxygen limitation was imposed. In the latter case the residual ammonium concentration was about $6 \mathrm{~mm}$ compared with about $21 \mathrm{~mm}$ in the former experiments. With the exception of succinate 
dehydrogenase, which did not decrease in activity compared with a maximum fall of some $70 \%$ when ammonium was added during the transition (Table 1), there was no evidence for significant repression of these enzymes by ammonium.

Our experiments also show that certain tricarboxylic acid cycle enzymes, such as citrate synthase, malate dehydrogenase and isocitrate dehydrogenase, respond to changes in d.o.t. which suggests that such behaviour is not a unique manifestation of nitrogen-fixing organisms displaying respiratory protection.

We thank the Science Research Council for the award of a research studentship to C. G. M., Dr M. Midgley for helpful discussion and Mrs Anne Pye for skilful technical assistance in some of the later experiments.

\section{REFERENCES}

CARTER, I. S. \& Dawes, E. A. (1979). Effect of oxygen concentration and growth rate on glucose metabolism, poly- $\beta$-hydroxybutyrate biosynthesis and respiration of Azotobacter beijerinckii. Journal of General Microbiology 110, 393-400.

Chaney, A. L. \& Marbach, E. P. (1962). Modified reagents for determination of urea and ammonia. Clinical Chemistry 8, 130-132.

Dalton, H. \& Postgate, J. R. (1969). Effect of oxygen on growth of Azotobacter chroococcum in batch and continuous culture. Journal of General Microbiology 54, 463-473.

Drozd, J. \& Postgate, J. R. (1970). Effects of oxygen on acetylene reduction, cytochrome content and respiratory activity of Azotobacter chroococcum. Journal of General Microbiology 63, 63-73.

Gornall, A. G., Bardawill, C. J. \& David, M. M. (1949). Determination of serum proteins by means of the biuret reaction. Journal of Biological Chemistry 177, 751-766.

HAAKeR, H. \& VeEger, C. (1976). Regulation of respiration and nitrogen fixation in different types of Azotobacter vinelandii. European Journal of Biochemistry 63, 499-507.

HARRISON, D. E. F. (1976). The regulation of respiration rate in growing bacteria. Advances in Microbial Physiology 14, 243-313.

HunT, J. C. \& Phibrs, P. V., JR (1977). Abstracts of the Annual Meeting of the American Society for Microbiology, abstract K5, p. 187.

JACKSON, F. A. \& DAwES, E. A. (1976). Regulation of the tricarboxylic acid cycle and poly- $\beta$-hydroxybutyrate metabolism in Azotobacter beijerinckii grown under nitrogen or oxygen limitation. Journal of General Microbiology 97, 303-312.

JONES, C. W. (1979). Energy metabolism in aerobes. In Microbial Biochemistry. International Review of Biochemistry, vol. 21, pp. 49-84. Edited by J. R. Quayle. Baltimore: University Park Press.

LANning, M. C. \& Cohen, S. S. (1951). The detection and estimation of 2-ketohexonic acids. Journal of Biological Chemistry 189, 109-114.

Midgley, M. \& Dawes, E. A. (1973). The regulation of transport of glucose and methyl $\alpha$-glucoside in Pseudomonas aeruginosa. Biochemical Journal 132, $141-154$.

NG, F. M.-W. \& DAwes, E. A. (1973). Chemostat studies on the regulation of glucose metabolism in
Pseudomonas aeruginosa by citrate. Biochemical Journal 132, 129-140.

PARKER, C. A. (1954). Effect of oxygen on nitrogen fixation by Azotobacter. Nature, London 173, 780-781.

Phillips, D. A. \& Johnson, M. J. (1961). Aeration in fermentations. Journal of Biochemical and Microbiological Technology and Engineering 3, 277-309.

RACKER, E. (1950). Spectrophotometric measurements of the enzymatic formation of fumaric and cisaconitic acids. Biochimica et biophysica acta 4, 211-214.

Roberts, B. K., Midgley, M. \& Dawes, E. A. (1973). The metabolism of 2-oxogluconate by Pseudomonas aeruginosa. Journal of General Microbiology 78, 319-329.

SENIOR, P. J. \& DAwEs, E. A. (1973). The regulation of poly- $\beta$-hydroxybutyrate metabolism in Azotobacter beijerinckii. Biochemical Journal 134, 225228.

Senior, P. J., BeEch, G. A., Ritchie, G. A. F. \& DAwEs, E. A. (1972). The role of oxygen limitation in the formation of poly- $\beta$-hydroxybutyrate during batch and continuous culture of Azotobacter beijerinckii. Biochemical Journal 128, 1193-1201.

Stephenson, M. P., Jackson, F. A. \& Dawes, E. A. (1978). Further observations on carbohydrate metabolism and its regulation in Azotobacter beijerinckii. Journal of General Microbiology 109, 89-96.

Stouthamer, A. H. (1978). Energy-yielding pathways. In The Bacteria, vol. 6, pp. 389-462. Edited by L. N. Ornston \& J. R. Sokatch. New York: Academic Press.

VEEGER, C., DER VARTANiAN, D. V. \& ZeYlemaker, W. P. (1969). Succinate dehydrogenase. Methods in Enzymology 13, 81-90.

von Tigerström, M. \& CAMpbell, J. J. R. (1966). The accumulation of $\alpha$-ketoglutarate by suspensions of Pseudomonas aeruginosa. Canadian Journal of Microbiology 12, 1005-1013.

Ward, A. C., Rowley, B. I. \& Dawes, E. A. (1977). Effect of oxygen and nitrogen limitation on poly$\beta$-hydroxybutyrate biosynthesis in ammoniumgrown Azotobacter beijerinckii. Journal of General Microbiology 102, 61-68.

Weitzman, P. D. J. \& Dunmore, P. (1969). Regulation of citrate synthase activity by $\alpha$-keto- 
glutarate. Metabolic and taxonomic significance. Whiting, P. H., Midgley, M. \& Dawes, E. A. FEBS Letters 3, 265-267.

Whiting, P. H., Midgley, M. \& Dawes, E. A. $(1976 a)$. The regulation of transport of glucose, gluconate and 2-oxogluconate and of glucose catabolism in Pseudomonas aeruginosa. Biochemical Journal 154, 659-668.

$(1976 b)$. The role of glucose limitation in the regulation of the transport of glucose, gluconate and 2-oxogluconate, and of glucose metabolism in Pseudomonas aeruginosa. Journal of General Microbiology 92, 304-310. 